\title{
Influence of NACL on the Micellar Behaviour of Some Cationic Surfactans
}

\author{
Pooja Vatta ${ }^{1 *}$, Rajwant Kaur ${ }^{1}$ \\ ${ }^{1 *}$ Department of chemistry, Dev Samaj Post Graduate College for women, ferozepur city, Punjab,India 152002 \\ ${ }^{I}$ Department of chemistry, Dev Samaj Post Graduate College for women, ferozepur city, Punjab,India 152002
}

\begin{abstract}
An attempt has made to study the influence of $\mathrm{NaCl}$ on the micellar behaviour of some cationic surfactants by conductivity measurements. With increase in concentration of salt, the critical micelle concentration $(C M C)$ of cetyltrimethylammoniumbromide (CTABr) decreases. For example, the CMCs of $\mathrm{CTABr}$ in 0.5,1, 2.5 and $5 \mathrm{mM}$ solutions of $\mathrm{NaCl}$ were 0.95, 0.89, 0.70, 0.51 respectively. The degree of dissociation i.e. $\boldsymbol{\beta}$ and Gibbs free energy of micellization, $\boldsymbol{\Delta \boldsymbol { G } ^ { o }}$ mic, was also determined for each $C M C$ value.
\end{abstract}

Key Words: Cetyltrimethyl ammoniumbromide, Cetylkonium chloride(CKC), $\mathrm{CMC}, \mathrm{KCl}$, micellization.

\section{Introduction}

Surfactants or surface active agents are the compounds which reduces the interfacial tension between two liquids or between a liquid and a solid. They can act as despersents, wetting agents, emulsifiers, foaming agents. Surfactants are the compounds that contain both hydrophobic group as their tails as well as hydrophilic groups as their head, so they are called amphiphilic[1-3]. Due to presence of hydrophobic and hydrophilic group, surfactants have both water insoluble and water soluble components. Depending on hydrophilic group, surfactants have been categorised into four different types[1]. Anionic Surfactants having negative charge on their hydrophilic end for example, soap, alkyl sulphate, Cationic Surfactants having positive charge on their hydrophilic end for example, alkyl quartenary system. Amphoteric surfactants are the compounds that contains both positive and negative charge on their water loving end, so they have a net charge of zero, for example, long chain amine and Non-ionic surfactants possess no ionic charge, for example, Alkoxylates, Ethoxylates[4-5].

Surface active agents lowers the interfacial tension of water by adsorbing at liquid-liquid or liquid-solid interface. Hydrophilic group i.e. water soluble component remains in water while the hydrophobic group i.e. water insoluble component extends out of the water phase. Aggregates formed by these surfactants are called micelles and formation of these micelles from surface active agents are called micellization[6]. The concentration of surfactants above which micelles begin to form is known as the critical micelle concentration[7].

Surface active agents have wide applications in different fields. Despite their use as industrial surfactants in pharmaceutical, textile and crude oil manufacturer industries, they are used as household surfactants in cleaning purposes. Being charged species they are sensitive to $\mathrm{pH}$. Some amphoteric surfactants are insensitive to $\mathrm{pH}$ while others are anionic at high $\mathrm{pH}$ and cationic at low $\mathrm{pH}$. To protect metal surfaces from water, acids and salts, cationic surfactants play crucial role by acting as corrosion inhibitors at $\mathrm{pH}$ below 7. One of the cationic surfactants such as N-Benzyl- N-alkyl dimethyl ammonium halides are used as disinfectants, sanitizers and germicides [1].

\section{Factors Affecting Critical Micelle Concentration}

II (a). Surfactant Structure : As the number of carbon atoms in the hydrophobic group increases, the CMC of surface active agents decreases. With addition of methylene group to a straight chain of hydrophobic group, CMC of surfactant halved. When number of carbon atoms exceeds 18, then no further decrease in CMC was found, this may due to the coiling of these hydrophobic chains [8]. Hydrophilic group also affects CMC of surfactant. When hydrophilic group is present at central position, CMC of surfactant increases [9]. II (b). Temperature: CMC of surface active agents is affected by temperature. With increase in temperature, $\mathrm{CMC}$ first decreases to some extent and then it increases with further increase in temperature[1]. II(c). Presence of added electrolyte in the solution: Presence of electrolyte in the aqueous solution affect CMC of surfactants .Effect is greater in case of cationic and anionic surfactant in comparison to amphoteric surfactants, which further has more effect than non-ionic surfactants $[10,11]$.

\section{Materials And Methods}

All the chemicals such as $\mathrm{CTAB}, \mathrm{NaCl}, \mathrm{CKC}$ were purchased from S.D fine chemicals limited, Mumbai. Distilled water with conductance 1-10 $\mu \mathrm{S}$ at room temperature was used for all measurements. All the solutions were prepared using distilled water. The aqueous solution of $\mathrm{NaCl}(0 \mathrm{Mm}, 0.5 \mathrm{Mm}, 1 \mathrm{mM}, 2.5 \mathrm{Mm})$ 
CTABr(10mM), CKC(10mM) was prepared by weighing appropriate amount of these two surfactants on an electronic balance with precision $.0001 \mathrm{~g}$. Digital conductivity meter was used to measure the Conductivities of solutions. A glass jacket containing conductivity cells having cell constant 1.17 and .99 with an uncertainty of $10 \%$ was used for carrying out the measurements.

\section{Results And Discussion}

CMC is denoted as breakpoint in plot between specific conductance and concentration as shown in fig. 1 and 2. The $\mathrm{CMC}$ value of $\mathrm{CTABr}$ and $\mathrm{CKC}$ determined at room temperature in water were found to lie close to literature values. The $\mathrm{CMC}$ values of $\mathrm{CTABr}$ and $\mathrm{CKC}$ were found to decrease with increase in concentration of Sodium chloride.

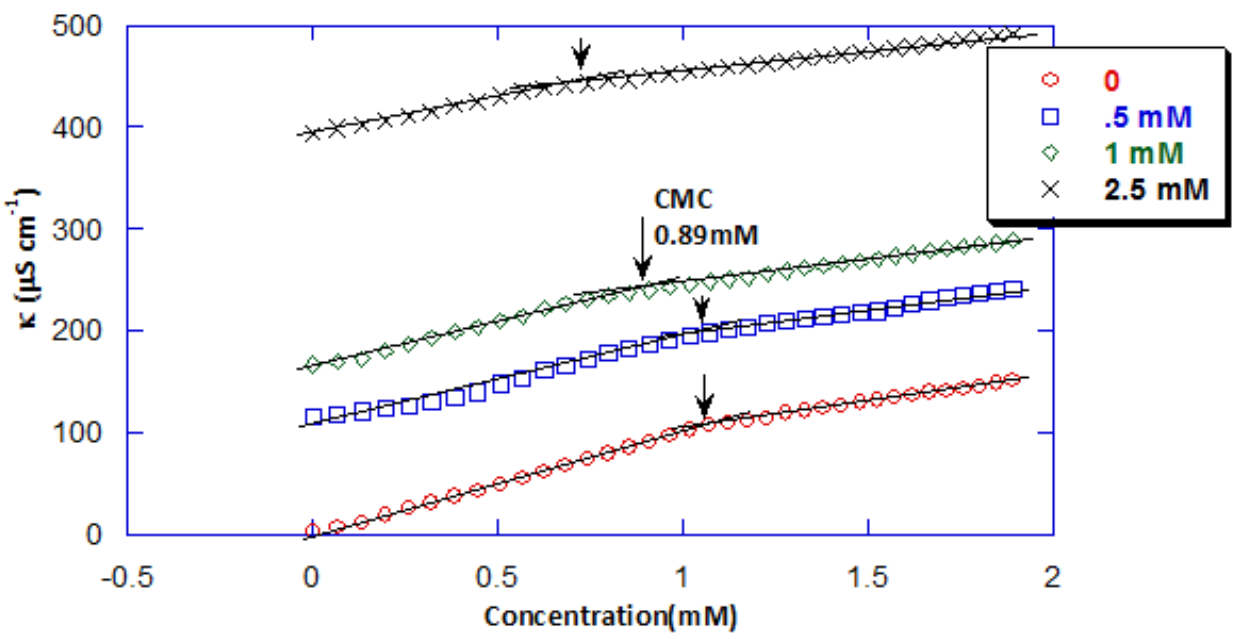

Fig. 1. Variation of specific conductance for CTABr with concentration of Sodium chloride

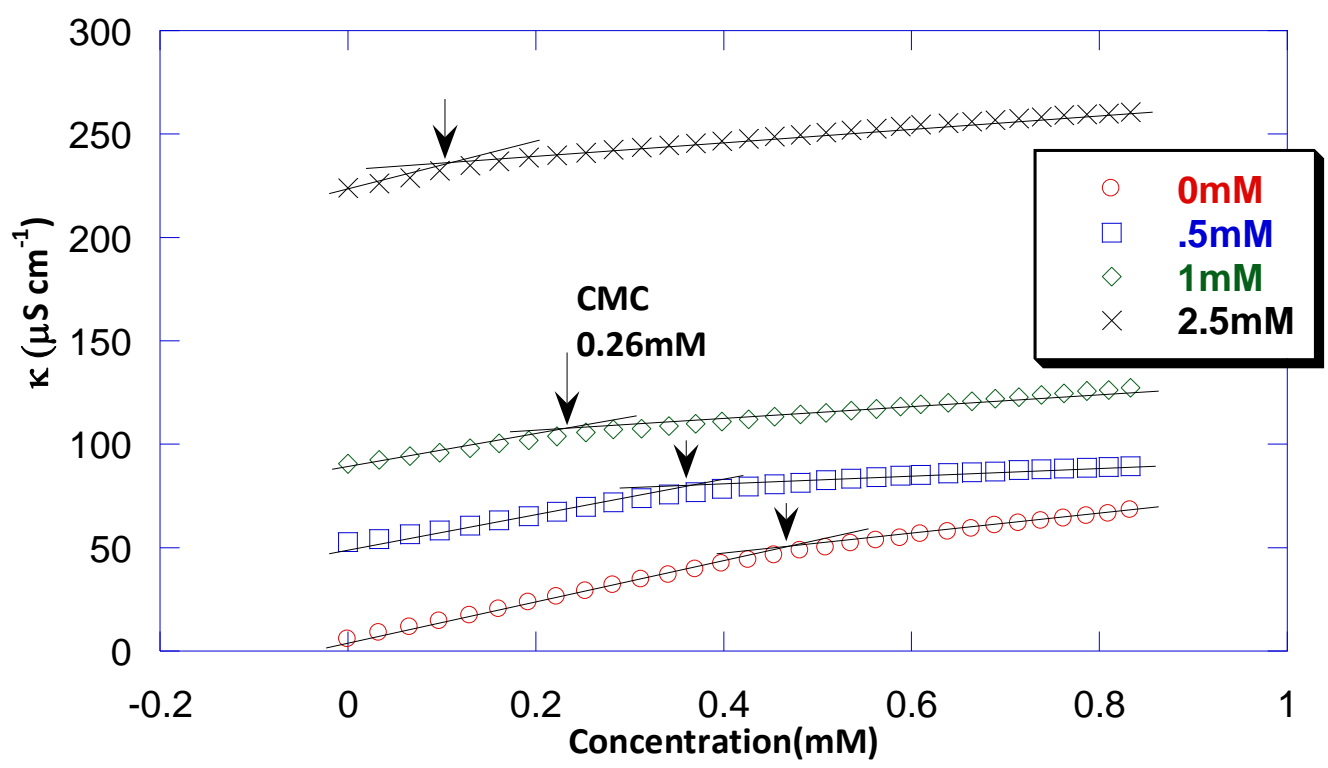

Fig. 2. Variation of specific conductance for $\mathrm{CKC}$ with concentration of Sodium chloride.

The degree of dissociation i.e. $\beta$ has been calculated by taking ratio of slopes of the post micellar region to the pre micellar region. The variation of $\beta$ value with increase in concentration of salt for CKC has been shown in fig. 3 . 


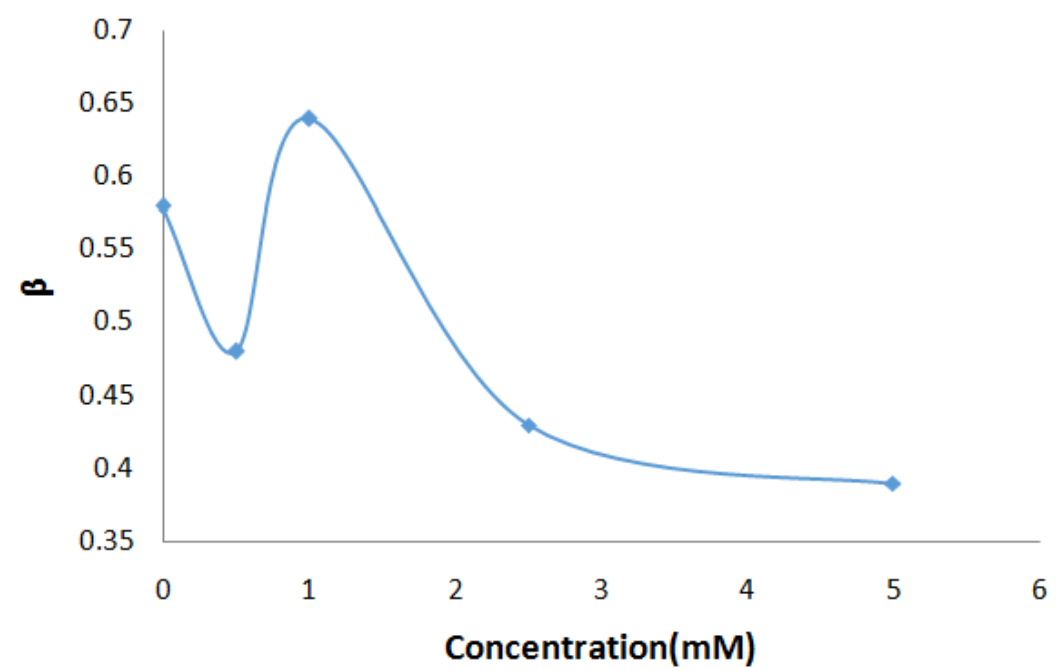

Fig. 3 Variation of $\beta$ values of $\mathrm{CKC}$ with concentration of $\mathrm{NaCl}$.

By knowing the value of degree of dissociation and CMC of surfactants, we can determine the standard Gibb's free energy of micellization per mole with the help of equation (1)

$$
\Delta \mathrm{G}_{\text {mic }}^{0}=(2-\beta) \mathrm{RT} \ln \mathrm{X}_{\mathrm{CMC}} \quad \text { (1) }
$$

$\Delta \mathrm{G}_{\text {mic }}^{0}$ - The standard Gibb's free energy of micellization per mole

$\mathrm{R}$ - Gas constant

$\mathrm{T}$ - Absolute temperature

$\mathrm{X}_{\mathrm{CMC}}-\mathrm{CMC}$ in mole fraction.

The calculated values of $\Delta \mathrm{G}^{0}$ mic in aqueous solution and in presence of salts at different concentration for CKC and $\mathrm{CTABr}$ is given in table 1 and 2 respectively. Negative value of $\Delta \mathrm{G}^{0}{ }_{\text {mic }}$ indicates the spontaneity of the micellization process. At high concentration of salt, $\Delta \mathrm{G}^{0}$ mic values for all surfactants become more negative i.e. $\Delta \mathrm{G}^{0}{ }_{\text {mic }}$ decreases with increase in concentration of salt. $\Delta \mathrm{G}^{0}$ mic values for CKC in presence of Sodium chloride are comparatively more negative than CTABr.

Table1: CMC and thermodynamic parameters of $\mathrm{CKC}$ in an aqueous solution (water) and Sodium chloride $(\mathrm{NaCl})$.

\begin{tabular}{|l|l|l|l|}
\hline Concentration of NaCl $(\mathbf{m M})$ & $\mathbf{C M C}(\mathbf{m M})$ & $\mathbf{B}$ & $\Delta \mathbf{G}^{\mathbf{0}}$ mic $^{\left(\mathbf{k J m}^{-1}\right)}$ \\
\hline 0 & 0.47 & 0.58 & -16.85 \\
\hline 0.5 & 0.36 & 0.48 & -19.05 \\
\hline 1 & 0.26 & 0.64 & -18.04 \\
\hline 2.5 & 0.17 & 0.43 & -22.48 \\
\hline 5 & 0.10 & 0.39 & -25.11 \\
\hline
\end{tabular}

Table 2: CMC and themodynamic parameters of CTABr in an aqueous solution (water), Sodium chloride $(\mathrm{NaCl})$

\begin{tabular}{|l|l|l|l|}
\hline Concentration of $\mathbf{N a C l}(\mathbf{m M})$ & $\mathbf{C M C}(\mathbf{m M})$ & $\mathbf{B}$ & $\Delta \mathbf{G}^{\mathbf{0}} \mathbf{m i c}^{\left(\mathbf{k J m o l}^{-1}\right)}$ \\
\hline 0 & 1.08 & 0.38 & -15.93 \\
\hline .5 & 0.95 & 0.36 & -16.41 \\
\hline 1 & 0.89 & 0.39 & -16.45 \\
\hline 2.5 & 0.70 & 0.40 & -17.52 \\
\hline 5 & 0.51 & 0.54 & -16.98 \\
\hline
\end{tabular}

\section{Conclusion}

The variation of CMC value of CTABr and CKC was studied in the presence Sodium chloride. With the increase in concentration of salt, the CMC values of these surfactants were found to be decreased. The degree of dissociation i.e. $\beta$ and Gibbs free energy of micellization,.$\Delta \mathrm{G}^{0}{ }_{\text {mic }}$ was also determined for each CMC value. The values of $\Delta \mathrm{G}^{0}$ mic were found to be negative which indicates that process of micellization is spontaneous. The . $\Delta \mathrm{G}_{\text {mic }}^{0}$ values become more negative at high concentration of salt.

\section{Acknowledgement}

We would like to thank Dr. Ashwani Kumar Sood, Department of Chemistry, Guru Nanak Dev University, and Amritsar for providing neccesary appratus and guidlines. 


\section{References}

[1]. Rosen, m.j and Kunjappu, J.T., "Surfactants and interfacial phenomena(4 ${ }^{\text {th }}$ ed.)." Hoboken, New Jersey: John Wiley \& Sons. p.1.2010.

[2]. Kosswig, K., "Surfactants" in Ullman's encyclopaedia of industrial chemistry, Wiley-VCH, Weinheim,2005

[3]. Harley, G.S., J. Phys. Chem. B, 46, 14955, 2010

[4]. Kuliszewska. E., Brecker. L., J Surfact Deterg, 17, 951, 2014.

[5]. McBain, J.W., Trans. Faraday Soc. 9, 99, 1913.

[6]. Kosswig, K.; \&quot;Surfactants\&quot; in Ullmann\&\#39;s Encyclopedia of Industrial Chemistry, Wiley-VCH, Weinheim 2005.

[7]. IUPAC. Compendium of Chemical Terminology, 2nd ed. (the "Gold Book"). Compiled by A. D. McNaught and A. Wilkinson. Blackwell Scientific Publications, Oxford (1997). XML on-line corrected version: http://goldbook.iupac.org (2006-) created by M Nic, J. Jirat, B. Kosata; updates compiled by A. Jenkins. ISBN 0-9678550-9-8. doi:10.1351/goldbook. Entry " critical micelle concentration, cmc.

[8]. Geiss, W., Fette, Seife, Anstrichm, 57, 24, 168, 236, 1955.

[9]. Evans, H.C., J. Chem. Soc. 579, 1956.

[10]. Yiv, S. and Zana, R., J. Colloid interface Sci. 77, 449, 1956

[11]. Mukerjee, P., Adv. Colloid Interface Sci. 77, 449, 1980.

[12]. Ray, A., Nature (London) 231, 313, 1971.

[13]. Rehfeild, S. J., J. Phys Chem. Soc. Faraday Trans. 1. 71, 738, 1967.

[14]. Vijayendran, B.R. and Brush, T.P., J. Colloid Interface Sci. 68, 383, 1979.

[15]. Murphey, D.S. and Rosen, M.J., J.Phys. Chem. 76, 3012, 1972.

[16]. Gabreil, O.R, Vishwanath, R., Michelle, A., Joy, M., Jeffry, J., Jiang, Y., Brendan, G., Andrew, B., Richard, F., Temple, F., Jarrel, A., Appl Microbial Biotechnol, 86, 1387, 2010.

[17]. Molina-Boli var, J. A., Hierrezuelo, J.M.and Ruiz, C. C., J.Phys. Chem. B, 110, 12089, 2006.

[18]. Baloch, M.K., Hameed, G. and Bano, A., J. Chem. Soc. Pak, 24,2,2002.

[19]. Ray, A., Nemethy, G., J. Am. Chem. Soc, 1,93,1971.

[20]. Carale, R. Teresa, Quynh , T. Pham and Blankschtein, D., Lamgmuir, 10,109,1994.

[21]. Ericson, C. A., O., Garamus, M.V., Bergstorm, M., Ulvenlund, S. Langmuir, 20,101, 2004. 